\title{
Exercise-induced bronchoconstriction in school-age children born extremely preterm
}

\author{
Isabelle Hamon ${ }^{1,2}$, Silvia Varechova ${ }^{2,3}$, Rachel Vieux', Iulia loan ${ }^{3}$, Claude Bonabel ${ }^{2,3}$, Cyril Schweitzer $^{2,3}$, Jean Michel Hascoet ${ }^{1,2}$ \\ and François Marchal ${ }^{2,3}$
}

BACKGROUND: School children born preterm often show airway hyperresponsiveness to methacholine or histamine. Less attention has been paid to their airway response to exercise, an important point because of the role of exercise in the child's daily life. The aim of this study was to describe the characteristics of, and potential determinants to, the airway response to exercise in children born extremely preterm.

METHODS: Forty-two nonasthmatic nonatopic children born before 32 wk gestation were compared with 27 healthy nonasthmatic nonatopic term children at age 7 . Spirometry and respiratory impedance were measured at baseline and repeated after a single-step 6-min treadmill exercise in a climate-controlled room.

RESULTS: The preterm group showed significant bronchoconstriction induced by exercise. Prematurity, but not low baseline lung function, neonatal oxygen supplementation, mechanical ventilation, chronic lung disease, or maternal smoking, was a determinant of exercise-induced bronchoconstriction.

CONCLUSION: Children born extremely preterm present significant exercise-induced airway obstruction at age 7. The response has different characteristics from that occurring in asthmatics and is likely to express airway noneosinophilic inflammation.

$S^{i}$ gnificant respiratory morbidity has been reported in schoolage children who were born prematurely in both the presurfactant and postsurfactant eras. This increased incidence of respiratory symptoms such as cough and wheeze has been studied in association with decreased lung function, increased bronchodilator responsiveness, and airway response to pharmacological stimuli such as methacholine or histamine (1-5). The airway response to exercise has received comparatively less attention.

Given the role of exercise in the child's daily life, such information is important for routine care. Airway narrowing may limit exercise capacity and must be differentiated from the deficient ventilatory adaptation to metabolic load that has been documented in some preterm-born children (6-9). It is commonly observed in the pediatric lung function lab that acute reduction in airway function triggered by a short bout of intense exercise may coincide with only minimal respiratory complaint. Thus, it is possible that exercise limitation by bronchoconstriction may be poorly signaled, undetected by questionnaires of epidemiological studies, and unreported to doctors, and could expose the child to life-threatening asthma attacks (10).

Airway inflammation is reportedly involved in the pathogenesis of chronic lung disease of prematurity (11), but it is unknown to what extent the related mechanisms are active later on or relevant to respiratory morbidity at school age. Identification of exercise-induced bronchoconstriction may help resolve this question, given that it is typically associated with airway inflammation (12). From a pathophysiological point of view, it is of interest to combine lung function assessment during expiratory flow limitation and tidal breathing by spirometry and the forced oscillation technique, respectively. The latter assesses the respiratory impedance to airflow, expressed as respiratory resistance (Rrs) related to frictional losses along the airways and respiratory reactance (Xrs) expressing, in the lower frequency domain, the apparent respiratory elasticity.

Our primary aim was to describe the airway response to a short treadmill exercise in a cohort of school-age children who were born very preterm. The secondary aims were to identify the factors possibly associated with airway hyperresponsiveness and to assess the pathophysiological mechanisms.

\section{RESULTS}

\section{Subjects}

Forty-two very prematurely born and 27 healthy children born at term were included in the study. The neonatal characteristics and demographics at school age are presented in Tables 1 and 2 , respectively. Age and height were similar between groups, but weight and body mass index were lower in patients as compared with controls $(P<0.003$ and $P<0.05$, respectively). The incidence of maternal smoking was not different between groups.

\section{Baseline Lung Function}

Forced vital capacity (FVC) was not significantly different between groups, in contrast to forced expiratory volume in $1 \mathrm{~s}$ (FEV1) and FEV1/FVC, which were significantly lower 
Table 1. Neonatal characteristics of the children

\begin{tabular}{lcc}
\hline & Premature & Control \\
\hline$N(\mathrm{M} / \mathrm{F})$ & $42(17 / 25)$ & $27(9 / 18)$ \\
$\mathrm{GA}^{\mathrm{a}}(\mathrm{wk})$ & $28.9 \pm 1.8$ & $39.7 \pm 1.2$ \\
Birth weight $^{\mathrm{a}}(\mathrm{kg})$ & $1.16 \pm 0.32$ & $3.26 \pm 0.42$ \\
Oxygen therapy & & \\
$N$ & 41 & - \\
Duration $^{\mathrm{b}}(\mathrm{d})$ & $51(1-451)$ & \\
Ventilatory support & & - \\
$N$ & 41 & \\
Duration $^{\mathrm{b}}(\mathrm{d})$ & $28(1-102)$ & \\
\hline
\end{tabular}

F, female; GA, gestational age; $M$, male.

${ }^{\mathrm{a}}$ Mean \pm SD. ${ }^{\mathrm{b}}$ Median (range).

Table 2. Characteristics of the children at follow-up

\begin{tabular}{|c|c|c|c|}
\hline & & Premature & Control \\
\hline$N$ & $y$ & 42 & 27 \\
\hline $\mathrm{Age}^{\mathrm{a}}$ & & $7.1 \pm 0.4$ & $7.0 \pm 0.6$ \\
\hline \multirow[t]{2}{*}{ Height $^{a}$} & $\mathrm{~cm}$ & $119 \pm 6$ & $122 \pm 6$ \\
\hline & $z$-score & $-0.41 \pm 1.16$ & $0.08 \pm 1.0$ \\
\hline \multirow[t]{2}{*}{ Weight $^{\mathrm{a}}$} & $\mathrm{kg}$ & $21.7 \pm 3.3^{*}$ & $24.3 \pm 3.5$ \\
\hline & $z$-score & $-0.49 \pm 1.10^{*}$ & $0.30 \pm 0.87$ \\
\hline \multirow[t]{2}{*}{ Body mass index } & & $15.3 \pm 1.8^{* *}$ & $16.3 \pm 1.4$ \\
\hline & $z$-score & $-0.35 \pm 1.12^{*}$ & $0.35 \pm 0.81$ \\
\hline Maternal smoking ${ }^{b}$ & & $12(28.5 \%)$ & $5(18.5 \%)$ \\
\hline
\end{tabular}

aMean \pm SD. ${ }^{b}$ Number (incidence). ${ }^{*} P \leq 0.01$ vs. controls. ${ }^{*} P<0.05$ vs. control.

Table 3. Lung function at follow-up

\begin{tabular}{llcc}
\hline & & Premature & Control \\
\hline Spirometry & & 42 & \\
$N$ & & $1.52 \pm 0.26$ & $1.63 \pm 0.30$ \\
FVC & $\mathrm{I}$ & $0.31 \pm 1.04$ & $0.41 \pm 0.71$ \\
& $z$-score & $1.36 \pm 0.24^{*}$ & $1.53 \pm 0.28$ \\
FEV1 & $\mathrm{I}$ & $0.18 \pm 1.05^{* *}$ & $0.68 \pm 0.81$ \\
& $z$-score & $90 \pm 8^{* *}$ & $94 \pm 4$ \\
FEV1/FVC & $\%$ & $-0.12 \pm 1.36^{* *}$ & $0.47 \pm 0.81$ \\
& $z$-score & & \\
Respiratory impedance & & 40 & 27 \\
$N$ & & $9.5 \pm 2.9^{* *}$ & $8.1 \pm 2.2$ \\
Rrsi & hPa.s/l & $10.6 \pm 3.9$ & $9.5 \pm 3.2$ \\
Rrse & hPa.s/l & $1.2 \pm 0.5$ & $1.0 \pm 0.8$ \\
Xrsi & hPa.s/l & $1.5 \pm 0.7$ & $1.3 \pm 0.9$ \\
Xrse & hPa.s/l & & \\
\hline
\end{tabular}

Data are mean \pm SD.

FEV1, forced expiratory volume in $1 \mathrm{~s}$; FVC, forced vital capacity; Rrse, respiratory resistance in expiration; Rrsi, respiratory resistance in inspiration; Xrse, respiratory reactance in expiration; Xrsi, respiratory reactance in inspiration.

${ }^{*} P \leq 0.01$ vs. control. ${ }^{* *} P<0.05$ vs. control.

in patients as compared with controls $(P<0.01$ and $P<0.05$, respectively, Table 3 ). Rrs in inspiration (Rrsi), but not in expiration (Rrse) or Xrs, was significantly larger in patients as compared with controls $(P<0.05$, Table 3$)$.
Table 4. Peak lung function response to exercise

\begin{tabular}{lcc}
\hline & Premature & Control \\
\hline Spirometry & & \\
$N$ & 42 & 27 \\
FVC (\%) & $-3.5 \pm 7^{*}$ & $0.7 \pm 3$ \\
FEV1 (\%) & $-4.4 \pm 6^{*}$ & $-0.2 \pm 3$ \\
Respiratory impedance & & \\
$N$ & 40 & 27 \\
Rrsi (\%) & $12 \pm 16$ & $9 \pm 15$ \\
Rrse (\%) & $11 \pm 20$ & $11 \pm 16$ \\
Xrsi (hPa.s/l) & $0 \pm 0.7$ & $0.1 \pm 0.6$ \\
Xrse (hPa.s/l) & $-0.2 \pm 1.3$ & $0.2 \pm 0.6$ \\
\hline
\end{tabular}

Data are mean \pm SD.

FEV1, forced expiratory volume in $1 \mathrm{~s}$; FVC, forced vital capacity; Rrse, respiratory resistance in expiration; Rrsi, respiratory resistance in inspiration; Xrse, respiratory reactance in expiration; Xrsi, respiratory reactance in inspiration.

${ }^{*} P \leq 0.01$ vs. controls.

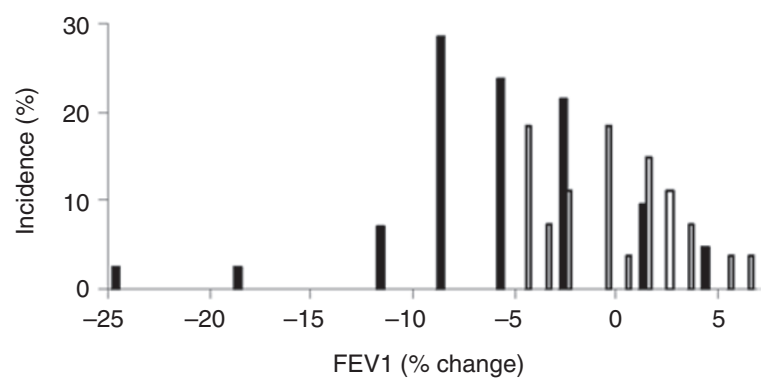

Figure 1. Distribution of airway responses to exercise showing more prevalent FEV1 decrease in children born prematurely (heavy bars) as compared with healthy children (light bars). FEV1, forced expiratory volume in $1 \mathrm{~s}$.

\section{Airway Response to Exercise}

One child from the premature group required salbutamol nebulization at $5 \mathrm{~min}$ after exercise for significant clinical response. Overall, FVC and FEV1 responses-but neither Rrs nor Xrs responses-were significantly larger in patients than in controls $(P<0.003$ and $P<0.001$, respectively; Table 4). Figure 1 shows the distribution of responses to exercise. There is a clear leftward shift in patients as compared with controls, in whom no FEV 1 decrease below $5 \%$ is found, which contrasts with $24 \%$ of the patients in whom an FEV1 decrease of $7 \%$ or more was found $(P<0.005)$. Within the former premature group, the FEV1 response to exercise was not different between those with and those without chronic lung disease in the neonatal period (Table 5) nor between those with and without a history of maternal smoking $(4.3 \pm 3.8 \%$ and $4.8 \pm 6.3 \%, P=0.8$, respectively). The multiple backward stepwise regression analysis identified gestational age $(P=0.002)$ - but not birth weight, duration of neonatal mechanical ventilation or oxygen support, current maternal smoking, or baseline lung function-as a determinant to the airway response to exercise.

\section{DISCUSSION}

The results of this study demonstrate significant exerciseinduced bronchoconstriction at school age in a cohort of extremely prematurely born children, using the recommended 
Table 5. Peak response to exercise in former preterm infants with and without CLD

\begin{tabular}{lcc}
\hline & CLD & No CLD \\
\hline Spirometry & 12 & \\
$N$ & $-1.6 \pm 6$ & $-4.3 \pm 7$ \\
FVC (\%) & $-3.1 \pm 6$ & $-4.9 \pm 6$ \\
FEV1 (\%) & & \\
Respiratory impedance & 11 & 29 \\
$N$ & $11 \pm 19$ & $12 \pm 15$ \\
Rrsi (\%) & $13 \pm 22$ & $11 \pm 20$ \\
Rrse (\%) & $0.1 \pm 0.8$ & $-0 \pm 0.7$ \\
Xrsi (hPa·s/l) & $0.1 \pm 0.9$ & $-0.3 \pm 1$ \\
Xrse (hPa·s/l) & & \\
\hline Data are mean \pm SD. & \\
CLD, neonatal chronic lung disease; FEV1, forced expiratory volume in 1 s; FVC, forced \\
vital capacity; Rrse, respiratory resistance in expiration; Rrsi, respiratory resistance \\
in inspiration; Xrse, respiratory reactance in expiration; Xrsi, respiratory reactance in \\
inspiration.
\end{tabular}

single-step treadmill protocol. Combined measurements of spirometry and respiratory impedance were performed, with both techniques demonstrating low lung function at baseline, whereas only spirometry indicated significant exercise-induced bronchoconstriction. The magnitude of the FEV1 response was indeed significantly larger in patients vs. controls, and the distribution of individual responses was clearly different between groups (Figure 1). In addition, it is worth noting that, in one child born prematurely, the clinical respiratory response required salbutamol nebulization after exercise. Nevertheless, former premature infants at school age in the current study appear to exhibit a pattern of response to exercise different from that reported in asthmatic children using the same protocol (13). Indeed, the magnitude of the FEV1 response to exercise observed in the latter was approximately two times larger, and the increase in Rrs was statistically significant (13). The transient bronchodilation occurring during hyperpnoea might in fact outlast the exercising period according to a shorter time course in asthmatics (14), in line with the attenuated bronchodilatory effect of a deep breath reported in these patients (15).

In asthmatics, after hyperpnoea induced by exercise-as well as by voluntary isocapnic hyperventilation-dehydration of the airway epithelium activates inflammation and the release of mediators eventually triggers bronchoconstriction (16). Similar mechanisms are involved in the bronchoconstriction induced by aerosols of mannitol, hypertonic saline, or adenosine $5^{\prime}$ monophosphate (16). Thus, these indirect airway challenges share the activation of inflammatory cells as a common pathway to airway narrowing (16). Airway inflammation has also been suggested to be involved in the development of neonatal chronic lung disease of prematurity (17), but its contribution to long-term respiratory function outcome is unknown $(3,11)$. In a comparative assessment of bronchial responsiveness in preschool children, those with a history of bronchopulmonary dysplasia were hyperresponsive to methacholine but not to adenosine $5^{\prime}$ monophosphate; asthmatics responded to both, and healthy controls to none (18). A positive adenosine $5^{\prime}$ monophosphate provocation test is associated with increased blood eosinophilia and serum IgE levels in typical asthma (19), so that the reported negative response to adenosine $5^{\prime}$ monophosphate in bronchopulmonary dysplasia (18) argues against a significant contribution of eosinophilic inflammation. These findings are in line with previous reports of nonelevated nitric oxide fraction in the expired gas in prematurely born children $(3,20,21)$. Furthermore, a detailed analysis of direct airway responsiveness/asthma characteristics in prematurely born children indicated significant differences from the typical childhood asthma (22).

Altogether, the data suggest that mechanisms not related to eosinophilic inflammation may account for the positive airway response to exercise in school-age children who were born prematurely. There is evidence that asthma is a heterogeneous condition and a substantial proportion of cases are not identified as the typical eosinophil-mediated disease (23). Noneosinophilic or neutrophilic phenotypes have been described $(23,24)$ and shown to correspond to different patterns of nonelevated nitric oxide fraction in the expired gas and degrees of airway responsiveness to mannitol (24). The evidence for exercise-induced bronchoconstriction in prematurely born children could relate to a condition different from eosinophilic asthma. Exercise-induced bronchoconstriction severity has been related to intensity of eosinophilic inflammation (25) but may also be observed in noneosinophilic asthma (26). In athletes, asthma may present either as the classical eosinophilic disease, with atopy, early onset in childhood, bronchial hyperresponsiveness, and increased nonelevated nitric oxide fraction in the expired gas. An alternative is late-onset asthma with variable nonelevated nitric oxide fraction in the expired gas and bronchoconstriction induced by eucapnic hyperventilation (27). Exposure of the respiratory epithelium to repeated thermal and evaporative losses with strenuous exercise bouts has been suggested to eventually trigger late-onset asthma (27). In a more general way, structural changes characteristic of airway remodeling may eventually result from bronchial hyperreactivity and/or eosinophilic or noneosinophilic inflammation (28). It is unknown whether the incidence and variety of airway/ lung injuries that occur during the early weeks of life in extremely preterm infants may have similar consequences. Inflammatory cells and mediators have in fact been recovered from tracheal fluid of preterm babies who eventually develop chronic lung disease (17), but topical steroids are rather inefficient in altering the course of the disease (29), and a course of inhaled steroids does not alter the airway hyperresponsiveness to histamine of schoolage children who were born prematurely (30).

The description of airway response to exercise of former premature infants at school age has so far been limited to a few children using graded protocols $(31,32)$. A larger FEV1 fall was first documented in prematurely born children with bronchopulmonary dysplasia as compared with controls (31). In the current study using a standardized absolute humidity environment, significant airway response to the single-step exercise was observed in those with and without a history of neonatal chronic lung disease. The current results are in line with the report that graded cycloergometer exercise is associated with an increased prevalence of $>15 \%$ decrease in FEV1 in children who were born extremely 
preterm, regardless of a history of bronchopulmonary dysplasia (32). Furthermore, the indirect bronchial hyperresponsiveness found in the current study is unrelated to duration of either neonatal oxygen supplementation or mechanical ventilation. In contrast, the hyperreactivity triggered by direct stimulation of airway smooth muscle histamine or acetylcholine receptors reported in prematurely born children $(1,4)$ is associated with severity of the neonatal condition, including a history of hyaline membrane disease (33) or bronchopulmonary dysplasia in infants born preterm (34) and extremely preterm $(2,35)$. In the Hammersmith cohort, more prevalent airway hyperresponsiveness to histamine was significantly related to poor airway function, and low histamine $\mathrm{PD}_{20}$ (dose that provokes $20 \%$ decrease in FEV1) was associated with low forced expiratory volume in $0.75 \mathrm{~s}$ (4). In our study, the exercise-induced airway hyperresponsiveness was not related to lung function or to a history of maternal smoking. Thus, prematurity is indicated to be a strong determinant of indirect airway reactivity at school age, independent of severity of neonatal respiratory distress, baseline lung function, or exposure to tobacco smoke.

From our data, we conclude that exercise-induced bronchoconstriction is present at school-age in nonatopic nonasthmatic children who were born extremely preterm. The indirect airway responsiveness is associated with prematurity itself rather than management at birth, chronic lung disease, baseline lung function, or maternal smoking $7 \mathrm{y}$ later. There are indications that the observed bronchoconstriction is likely to be related to noneosinophilic airway inflammation. It may be of practical importance to identify the detailed characteristics of the bronchoconstriction induced by exercise in children born prematurely, because the reported variety of asthma phenotypes is associated with a range of responses to treatment $(26,36)$. Further studies are needed to more precisely identify the cellular mechanisms and optimize the therapeutic approach to exercise-induced bronchoconstriction in these patients.

\section{METHODS}

\section{Patients}

This prospective monocenter follow-up study included premature infants born before $32 \mathrm{wk}$ gestational age in the Neonatology Department (Maternité Régionale Universitaire, Nancy, France) between July 1999 and February 2001. The cohort was initially nested in a large randomized controlled trial to assess the safety and efficacy of inhaled nitric oxide treatment within $48 \mathrm{~h}$ of birth for severe hypoxemic respiratory failure in very preterm infants (37). Durations of oxygen and mechanical ventilatory support and incidence of chronic lung disease, defined as need for oxygen support beyond the corrected age of $36 \mathrm{wk}$ (38), had been documented from the neonatal records. The survivors not treated with inhaled nitric oxide were studied at 7 $y$ of age. Age-matched healthy children born at term were recruited from local primary schools during the same period (39). The medical record included items relative to atopy, asthma, and current maternal smoking status. Atopy was defined as a history of allergic dermatitis or rhinoconjunctivitis, increased serum $\operatorname{IgE}(>200 \mathrm{IU} / \mathrm{ml})$, or positive responses to skin prick test. The following allergens were tested: grass, tree and weed pollen, dust mites, molds, and pet dander. A positive response was identified when the wheal diameter difference between control and specific allergen was at least $3 \mathrm{~mm}$. Asthma was identified by a medical history positive for one or more of the following symptoms during the past year: (i) wheeze at rest; (ii) cough, dyspnea, or wheeze on exertion; and (iii) beneficial use of antiasthma medications.
The children were seen at the follow-up clinic by senior pediatricians. All of them were free of respiratory symptoms at time of the testing. Height and weight were measured, and $z$-scores for height, weight, and body mass index were computed. The children underwent a standardized clinical examination and pulmonary function testing, as described below.

Both patient and control group criteria included a medical history negative for atopy and asthma. Written informed consents were obtained from the children and their parents at the time of lung function testing. The study was approved by the ethics committee (Comité de Protection des Personnes de Lorraine) and registered with the ClinicalTrials.gov registry (no. NCT00390065).

\section{Measurements and Exercise Challenge}

The lung function techniques and exercise protocol have been described in detail in a previous report (39). Briefly, respiratory mechanical impedance was measured using a $12 \mathrm{~Hz}$ sine wave pressure oscillation applied around the child's head to minimize upper airway shunting. Respiratory resistance and reactance were computed in inspiration (Rrsi, Xrsi) and expiration (Rrse, Xrse).

Forced spirometry was performed using an electronic flowmeter with computer animation programs (Masterscope, Erich Jaeger, Wuertzburg, Germany). Baseline FVC, FEV1, and the ratio of FEV1 to FVC were expressed as $z$-scores using recently published algorithms (40).

Lung function measurements were obtained at baseline and repeated $5 \mathrm{~min}$ and $15 \mathrm{~min}$ after a 6-min run on a treadmill in a climate-controlled room (absolute humidity $<10 \mathrm{mg} / \mathrm{l}(16)$ ). The response to exercise was computed using the largest of the two postexercise responses, and expressed as percentage change from baseline, except for Xrs, which was expressed as absolute difference because the baseline is frequently close to zero.

\section{Data Analysis}

An ANOVA was used for group comparison of biometrics, baseline lung function, and response to exercise. Patients were compared with controls and, within the premature group, children with and without a history of chronic lung disease were compared. Stepwise backward linear regression analysis was used to test for an association between airway response to exercise as the dependent variable and gestational age, birth weight, duration of neonatal mechanical ventilation and oxygen support, current maternal smoking status, and baseline lung function at follow-up as independent variables. Incidence of FEV1 responses to exercise was compared between groups using $\chi^{2}$ test. A statistically significant difference was retained at $P<0.05$.

\section{ACKNOWLEDGMENTS}

The authors thank the children who contributed to the study and their families and gratefully acknowledge the technical assistance of Bruno Demoulin, Sylvie Méline, Françoise Bebon, Marie Jeanne Arnoux, Marianne Mougin, and Francine Cael.

\section{STATEMENT OF FINANCIAL SUPPORT}

This study was supported by grant MESR EA3450 (Ministère de I'Enseignement Supérieur et de la Recherche) and the "Research and Teaching Supports for Neonatal Care Foundation" (APRESAN).

Disclosure: The authors declare no conflict of interest.

\section{REFERENCES}

1. Narang I, Baraldi E, Silverman M, Bush A. Airway function measurements and the long-term follow-up of survivors of preterm birth with and without chronic lung disease. Pediatr Pulmonol 2006;41:497-508.

2. Fawke J, Lum S, Kirkby J, et al. Lung function and respiratory symptoms at 11 years in children born extremely preterm: the EPICure study. Am J Respir Crit Care Med 2010;182:237-45.

3. Lum S, Kirkby J, Welsh L, Marlow N, Hennessy E, Stocks J. Nature and severity of lung function abnormalities in extremely pre-term children at 11 years of age. Eur Respir J 2011;37:1199-207.

4. Chan KN, Elliman A, Bryan E, Silverman M. Clinical significance of airway responsiveness in children of low birthweight. Pediatr Pulmonol 1989;7: $251-8$. 
5. Chan KN, Elliman A, Bryan E, Silverman M. Respiratory symptoms in children of low birth weight. Arch Dis Child 1989;64:1294-304.

6. Hebestreit H, Bar-Or O. Exercise and the child born prematurely. Sports Med 2001;31:591-9.

7. Welsh L, Kirkby J, Lum S, et al.; EPICure Study Group. The EPICure study: maximal exercise and physical activity in school children born extremely preterm. Thorax 2010;65:165-72.

8. Smith LJ, van Asperen PP, McKay KO, Selvadurai H, Fitzgerald DA. Reduced exercise capacity in children born very preterm. Pediatrics 2008;122: e287-93.

9. Baraldi E, Carraro S. Exercise testing and chronic lung diseases in children. Paediatr Respir Rev 2006; 7:Suppl 1:S196-8.

10. Schweitzer C, Marchal F. Dyspnoea in children. Does development alter the perception of breathlessness? Respir Physiol Neurobiol 2009;167:144-53.

11. Bush A, Tiddens H, Silverman M. Clinical implications of inflammation in young children. Am J Respir Crit Care Med 2000;162(2 Pt 2):S11-4.

12. Anderson SD. How does exercise cause asthma attacks? Curr Opin Allergy Clin Immunol 2006;6:37-42.

13. Schweitzer C, Abdelkrim IB, Ferry H, Werts F, Varechova S, Marchal F. Airway response to exercise by forced oscillations in asthmatic children. Pediatr Res 2010;68:537-41.

14. Milanese M, Saporiti R, Bartolini S, et al. Bronchodilator effects of exercise hyperpnea and albuterol in mild-to-moderate asthma. J Appl Physiol 2009;107:494-9.

15. Pyrgos G, Scichilone N, Togias A, Brown RH. Bronchodilation response to deep inspirations in asthma is dependent on airway distensibility and air trapping. J Appl Physiol 2011;110:472-9.

16. Anderson SD. Indirect challenge tests: Airway hyperresponsiveness in asthma: its measurement and clinical significance. Chest 2010;138(2 Suppl):25S-30S.

17. Kotecha S, Wangoo A, Silverman M, Shaw RJ. Increase in the concentration of transforming growth factor beta- 1 in bronchoalveolar lavage fluid before development of chronic lung disease of prematurity. J Pediatr 1996;128: 464-9.

18. Kim do K, Choi SH, Yu J, Yoo Y, Kim Bl, Koh YY. Bronchial responsiveness to methacholine and adenosine $5^{\prime}$-monophosphate in preschool children with bronchopulmonary dysplasia. Pediatr Pulmonol 2006;41: $538-43$.

19. Bakirtas A, Turktas I. Airway hyper-responsiveness to adenosine 5'monophosphate in preschool-age children with asthma. Pediatr Allergy Immunol 2006;17:428-34.

20. Mieskonen ST, Malmberg LP, Kari MA, et al. Exhaled nitric oxide at school age in prematurely born infants with neonatal chronic lung disease. Pediatr Pulmonol 2002;33:347-55.

21. Baraldi E, Bonetto G, Zacchello F, Filippone M. Low exhaled nitric oxide in school-age children with bronchopulmonary dysplasia and airflow limitation. Am J Respir Crit Care Med 2005;171:68-72.

22. Halvorsen T, Skadberg BT, Eide GE, Røksund O, Aksnes L, Øymar K. Characteristics of asthma and airway hyper-responsiveness after premature birth. Pediatr Allergy Immunol 2005;16:487-94.
23. Wang F, He XY, Baines KJ, et al. Different inflammatory phenotypes in adults and children with acute asthma. Eur Respir J 2011;38:567-74.

24. Porsbjerg C, Lund TK, Pedersen L, Backer V. Inflammatory subtypes in asthma are related to airway hyperresponsiveness to mannitol and exhaled NO. J Asthma 2009;46:606-12.

25. Hallstrand TS, Moody MW, Aitken ML, Henderson WR Jr. Airway immunopathology of asthma with exercise-induced bronchoconstriction. J Allergy Clin Immunol 2005;116:586-93.

26. Cowan DC, Hewitt RS, Cowan JO, et al. Exercise-induced wheeze: Fraction of exhaled nitric oxide-directed management. Respirology 2010;15: 683-90.

27. Haahtela T, Malmberg P, Moreira A. Mechanisms of asthma in Olympic athletes-practical implications. Allergy 2008;63:685-94.

28. Baraldo S, Turato G, Bazzan E, et al. Noneosinophilic asthma in children: relation with airway remodelling. Eur Respir J 2011;38:575-83.

29. Kinsella JP, Greenough A, Abman SH. Bronchopulmonary dysplasia. Lancet 2006;367:1421-31.

30. Chan KN, Silverman M. Increased airway responsiveness in children of low birth weight at school age: effect of topical corticosteroids. Arch Dis Child 1993;69:120-4.

31. Santuz P, Baraldi E, Zaramella P, Filippone M, Zacchello F. Factors limiting exercise performance in long-term survivors of bronchopulmonary dysplasia. Am J Respir Crit Care Med 1995;152(4 Pt 1):1284-9.

32. Kriemler S, Keller H, Saigal S, Bar-Or O. Aerobic and lung performance in premature children with and without chronic lung disease of prematurity. Clin J Sport Med 2005;15:349-55.

33. Cano A, Payo F. Lung function and airway responsiveness in children and adolescents after hyaline membrane disease: a matched cohort study. Eur Respir J 1997;10:880-5.

34. Pelkonen AS, Hakulinen AL, Turpeinen M. Bronchial lability and responsiveness in school children born very preterm. Am J Respir Crit Care Med 1997;156(4 Pt 1):1178-84.

35. Korhonen P, Laitinen J, Hyödynmaa E, Tammela O. Respiratory outcome in school-aged, very-low-birth-weight children in the surfactant era. Acta Paediatr 2004;93:316-21.

36. Green RH, Brightling CE, Woltmann G, Parker D, Wardlaw AJ, Pavord ID. Analysis of induced sputum in adults with asthma: identification of subgroup with isolated sputum neutrophilia and poor response to inhaled corticosteroids. Thorax 2002;57:875-9.

37. Hamon I, Fresson J, Nicolas MB, Buchweiller MC, Franck P, Hascoet JM. Early inhaled nitric oxide improves oxidative balance in very preterm infants. Pediatr Res 2005;57(5 Pt 1):637-43.

38. Allen J, Zwerdling R, Ehrenkranz R, et al.; American Thoracic Society. Statement on the care of the child with chronic lung disease of infancy and childhood. Am J Respir Crit Care Med 2003;168:356-96.

39. Marchal F, Schweitzer C, Werts F, Vu LT, DeMoulin B, Nguyen YT. Postexercise airway narrowing in healthy primary school children. Pediatr Res 2008;63:328-31.

40. Stanojevic S, Wade A, Stocks J, et al. Reference ranges for spirometry across all ages: a new approach. Am J Respir Crit Care Med 2008;177:253-60. 